\title{
High-Expenditure Disease in the EU-28: Does Drug Spend Correspond to Clinical and Economic Burden in Oncology, Autoimmune Disease and Diabetes?
}

\author{
Wolfgang Greiner ${ }^{1}$ (I) $\cdot$ Keyur Patel ${ }^{2} \cdot$ Christina-Jane Crossman-Barnes $^{2} \cdot$ Troels Vingtoft Rye-Andersen $^{3}$. \\ Christian Hvid ${ }^{3} \cdot$ Tom Vandebrouck $^{4}$
}

Accepted: 20 December 2020 / Published online: 7 January 2021

(c) The Author(s) 2021

\begin{abstract}
Background Drug costs are increasing in Europe, and there is a heightened need to reduce pressure on healthcare systems. In 2017, oncology, autoimmune disease, and diabetes featured as the three highest therapy areas for drug spend in the EU-28. However, the absolute 1-year drug spend growth for diabetes did not feature within the ten fastest growing therapy areas. Objective This study explores the association between drug spend and disease burden in oncology, autoimmune disease, and diabetes in the EU-28.

Methods Oncology, autoimmune disease and diabetes therapeutic areas were investigated using four methodologies. Historical and forecasted drug spend was analysed using the IQVIA MIDAS ${ }^{\circledR}$ drug sales database. Clinical and economic burden was estimated from targeted literature reviews. Trend analyses compared changes in drug spend with clinical burden using the Global Burden of Disease tool as the epidemiological reference. Cost per quality-adjusted life-years (QALYs) from UK health technology assessments were compared to interpret the health economic value.

Results Oncology had the highest historical drug spend and growth compared with autoimmune disease and diabetes. Total drug spend and growth in oncology is forecasted to exceed diabetes by twofold. Increasing oncology drug spend historically did not correspond with reductions in mortality and morbidity. Diabetes had the lowest drug spend and greatest QALY/€1000 spent benefit.

Conclusion This study indicates that drug spend may not correlate to clinical burden across diseases. Future research could stimulate debate on whether more equitable drug funding may improve disease management.
\end{abstract}

\section{Key Points for Decision Makers}

Total healthcare costs in diabetes are high, despite low drug spend, so better disease management may result in cost savings elsewhere.

Future research could consider the equitable prioritisation and allocation of resources, given that diabetes drug spend does not correspond to its clinical burden.

High historical drug spend and spend growth in oncology does not appear to correspond with changes in its clinical burden.
Supplementary Information The online version contains supplementary material available at https://doi.org/10.1007/s4166 9-020-00253-4.

Wolfgang Greiner

wolfgang.greiner@uni-bielefeld.de

1 Department for Health Economics, Bielefeld University, Bielefeld, Germany

2 IQVIA Ltd, HEOR, London, UK

3 Novo Nordisk Region Europe Pharmaceuticals A/S, Copenhagen, Denmark

4 Novo Nordisk Region Europe Pharmaceuticals A/S, Brussels, Belgium 


\section{Introduction}

Healthcare systems in Europe and worldwide are under pressure to manage escalating drug costs. Driving factors include increased use of drugs due to changing lifestyles and demographics, rising patient expectations, stricter treatment targets, innovation and new product launches [1]. According to figures from the Organisation for Economic Co-operation and Development (OECD), expenditure on drugs in the EU-5 accounted for almost one-fifth of the total healthcare spend in 2018 (UK $11.9 \%$; France 13.2\%; Germany 14.1\%; Italy $17.5 \%$; Spain $18.6 \%$ ) [2].

New product launches with premium prices are largely responsible for escalating costs. Prices of new oncology drugs have risen substantially over the past decade, and many new products are currently in the developmental pipeline $[3,4]$. The increasing expenditure on drugs, particularly oncology drugs, has prompted much debate about both reducing costs and planning pharmaceutical expenditure to gain the maximum benefit for patients [1, 3-5].

A previous analysis using 2017 data from the IQVIA MIDAS $^{\circledR}$ drug sales database indicated that, across the EU-28, drug spend was greatest in three therapeutic areas: oncology (\$US29 billion), autoimmune disease (\$US13 billion) and diabetes (\$US10 billion) [6]. While oncology (44\%) and autoimmune disease (17\%) also appeared within the first ten therapeutic areas for the highest absolute 1-year drug spend growth, diabetes did not feature within the top ten therapy areas. Therefore, given the differences in disease ranking between total drug spend and absolute 1-year drug spend growth in 2017, this analysis led to the objective of this study. The objective of this study was to explore the relationship between drug spend and the clinical and economic disease burden associated with oncology, autoimmune disease and diabetes in the EU-28.

\section{Methods}

Oncology, autoimmune disease and diabetes were defined according to the World Health Organization (WHO) anatomical therapeutic chemical (ATC) classification codes (Table 1 in the electronic supplementary material [ESM]). Oncology included all ATC3 codes covering traditional chemotherapies (e.g. alkylating agents and antimetabolites) and new agents (e.g. immuno-stimulating agents and interferons). Autoimmune disease included ATC3 codes and psoriasis products covering special anti-rheumatic drugs, anti-tumour necrosis factor (TNF) agents and specific drugs such as apremilast and secukinumab. Rheumatoid arthritis (RA), psoriasis and inflammatory bowel disease (IBD) were selected as representative of autoimmune diseases based on drug spend by value, and all relevant codes were included. Diabetes included WHO ATC4 codes covering all insulins, all injectables and all oral antidiabetic drugs. The European summary of product characteristics for specific drugs was checked to determine their licensed indications.

\subsection{Drug Sales Forecasting Approach}

The IQVIA MIDAS ${ }^{\circledR}$ drug sales database was used to estimate historical drug sales (2012-2017), whereas future drug sales (2018-2022) were estimated using a forecasting model based on the historical data [6]. Historical sales volume and price per standard unit were calculated by region (EU-5, Nordics, Western Europe, Central Europe, Eastern Europe and Southern Europe) in Euros $(€)$. Exponential smoothing ensured that data from more recent years were weighted more heavily than older data, and extrapolation factors were used where complete coverage was unavailable. Historical sales were trended forward based on an awareness of market dynamics, such as new product launches and loss of exclusivity of branded products, which were subsequently accounted for. To inform this approach, analyses were conducted of pipeline products expected to launch in Europe and existing branded products expected to lose exclusivity over the 2018-2022 period. Medical devices were not included in the analysis, and the analysis took no account of manufacturer discounting or policy initiatives. The full forecasting methodological approach can be found in Fig. 1 in the ESM.

\subsection{Targeted Literature Review Search Process}

Targeted literature searches were performed in the Embase and MEDLINE databases using the OVID platform to understand the epidemiology and economic burden of each therapy area from 2008 to 2017. Additional grey literature searches were conducted to supplement epidemiology and economic findings for the same time period, with sources including the International Diabetes Federation (IDF), the Global Burden of Disease (GBD) tool and the WHO.

The searches were designed to establish the epidemiology (incidence and prevalence, mortality and morbidity; years of life lost [YLL], years lived with disease [YLD] and disability-adjusted life years [DALYs]) and economic burden. Titles and abstracts were screened for inclusion by one independent reviewer, followed by full-text screening, and $10 \%$ of the articles were double reviewed for accuracy. Articles were excluded if they did not specifically report data for the EU-28 or Europe (e.g. if they reported EU-3, EU-5, country level, etc.) or were published before 2007. The inclusion criteria are shown in Table 2 in the ESM, and the search strategies are shown in Tables 3, 4 and 5 in the ESM. 
Epidemiology and economic parameters were extracted from the published and grey literature for each therapy area. The included studies were those that had an EU-28 or European geographical coverage, and studies were quality assessed to ensure suitability in the analysis. Quality assessment criteria included study sample size, disease population and robustness of the methodological approach. Countrylevel studies were not included since extrapolation to the EU-28 level may not be representative across the region. Epidemiology estimates were taken from the published literature and an average estimate calculated. This was appropriate where data were reported for the entire disease of interest, for example, all oncology or diabetes. Weight adjustments were applied where appropriate, for example by considering the size of individual disease populations within autoimmune disease using a common population as taken from the GBD tool. IQVIA MIDAS ${ }^{\circledR}$ drug sales data were also included in the drug cost estimate for 2017 given data were available for each of the EU-28 countries. Where required, costs were inflated to 2017 values, converted to $€$ using the consumer price index (CPI) and adjusted using purchasing power parity (PPP) $[7,8]$. Where applicable, population or per patient costs were adjusted using the GBD prevalence tool to allow for studies to be extrapolated using a consistent population size. Average costs per year (drug, total direct [drug costs and non-drug costs] and other direct costs [non-drug costs]) were estimated across included studies in each therapy area as per-year costs were considered more relevant for policy- and budget-planning discussions.

\subsection{Economic and Epidemiological Trend Analyses}

IQVIA MIDAS ${ }^{\circledR}$ drug sales data and data from the GBD tool were used to compare changes in drug spend with changes in incidence, prevalence and mortality from 2012 to 2016 in all three therapy areas [6,9]. At the time of analysis 2012-2016 data from the GBD tool were the latest available for the trend analyses comparison, which was suitable to compare against the historical drug sales analyses from the IQVIA MIDAS ${ }^{\circledR}$ database. Drug spend trend analyses were performed per year as this provides more comparability given the differing age of onset and life expectancy of these patients.

\subsection{Value-of-Spend Analyses}

The value of medical expenditure was evaluated by assessing ten of the most recent UK heath technology assessment (HTA) submissions with positive and negative recommendations in each therapy area from either the National Institute for Health and Care Excellence (NICE) or the Scottish Medicines Consortium (SMC) with publication dates ranging from 2007 to 2018 [10-39]. This was an exploratory analysis conducted to better understand the health economic benefit and explore the incremental cost-effectiveness ratio (ICER) range across the three therapeutic areas. The HTA submissions were chosen to be reflective of the reimbursed landscape at the time of analysis. Analysing older submissions may not have been reflective of the current health economic value due to drug price changes. The base-case incremental costs and incremental quality-adjusted life-years (QALYs) generated from these submissions were extracted to determine the QALY gain per $€ 1000$ spent. This was estimated by determining the reciprocal of the ICER multiplied by 1000 (incremental QALYs divided by incremental costs) and converted from GBP (£) to $€$ using the 2018 exchange rate (1.14) and CPI at the time of analysis. Since the QALY incorporates both the quality and the quantity of life, it was considered an appropriate measure to determine the health economic value $[40,41]$. While a weighted average of ICERs according to market share may indicate the value of therapies across a disease, individual patients will only receive specific treatments. Therefore, an unadjusted average was considered appropriate to estimate the expected value patients would receive.

\section{Results}

\subsection{Historical Drug Sales (2012-2017)}

Across the EU-28, gross sales in oncology rose from $€ 18.0$ billion in 2012 to $€ 30.2$ billion in 2017 (11\% increase in compound annual growth rate $[\mathrm{CAGR}])$. Autoimmune disease and diabetes also rose from $€ 6.1$ billion to $€ 10.9$ billion (12\% CAGR increase) and from $€ 4.6$ billion to $€ 6.3$ billion (6\% CAGR increase), respectively.

In oncology and diabetes, the overall growth in sales volume was low (approximately $3 \%$ and $2 \%$, respectively, per year). The growth in oncology spend was mainly driven by high price launches of new molecules. Branded products remained the largest contributors to drug spend in diabetes; however, several product groups, for example, glucagon-like peptide-1 (GLP-1) analogues, experienced significant price declines. In contrast, volume growth in the autoimmune market was considerably higher, at $6 \%$. Awareness of autoimmune conditions has grown substantially in recent years, and several new indications for current and new products (e.g. secukinumab and vedolizumab) have received regulatory approval [6]. Volume growth was driven primarily by anti-TNF agents and speciality anti-rheumatic agents. Although pricing of most products in the autoimmune market remained stable, new product launches increased the average price, and high sales volumes of speciality antirheumatic agents heightened the impact of price increases 
on the overall market value [6]. The autoimmune market remained dominated by branded products, although the generics segment grew rapidly [6].

\subsection{Forecast Drug Sales (2018-2022)}

From 2018 to the end of the forecasted period (2022), drug sales were projected to rise from $€ 30.2$ billion to $€ 43.6$ billion in oncology (8\% CAGR increase), from $€ 10.9$ billion to $€ 13.6$ billion in autoimmune disease (5\% CAGR increase), and from $€ 6.3$ billion to $€ 7.7$ billion in diabetes (4\% CAGR increase). Within the three therapy areas, spending on oncology drugs is expected to account for $76 \%$ of the increase in drug spend from 2017 to 2022.

In oncology, new monoclonal antibody anti-neoplastic therapies and chimeric antigen receptor T-cell (CARTT) therapy with improved efficacy and safety profiles are expected to drive price increases, although this will be mitigated by stable prices and loss of exclusivity in other market segments. In addition, launches of new targeted therapies are expected to promote volume growth, which typically show survival benefits and in turn achieve price premiums. New product launches in psoriatic disease and expansion of indications for current products are expected to promote volume growth in autoimmune disease. However, new products are predicted to launch at similar prices to existing products, so no overall price increases are anticipated over the analysis period. Indeed, drug spend growth will likely be dampened by the market entry of biosimilars, with approximately 25-30\% discounts [6]. Price premiums are difficult to achieve in autoimmune disease, primarily because of limited unmet need and new products generally not providing significant survival benefits. Slower drug spend growth in diabetes is likely to result from stable prices of existing products and little impact on pricing due to loss of exclusivity. New products are expected to be launched at similar prices to current products, as significant survival benefits are generally not achieved. However, pipeline products in the GLP-1 and sodium-glucose co-transporter-2 (SGLT-2) inhibitor classes are likely to be key drivers of increases in drug sales volume due to increasing patient numbers.

\subsection{Targeted Literature Review Results}

\subsubsection{Epidemiology Findings}

Oncology had the highest annual incidence across the EU-28 (3.0 million patients per year) compared with 1.2 million for autoimmune diseases and 1.3 million for diabetes [9, 42-45]. However, the prevalence of diabetes was substantially higher (29.2 million patients per year) than either autoimmune disease (12.8 million) or oncology (9.4 million) $[9,46]$. Oncology was associated with the highest mortality rate of 127 per 100,000 population per year compared with 17 per 100,000 for diabetes and 2 per 100,000 for autoimmune diseases [9, 45, 47-49]. Across Europe, approximately one-quarter of all deaths were attributable to oncology $(25.6 \% ; 1.49$ million deaths), and approximately 1 in 50 deaths were attributable to diabetes ( $1.8 \%$; 0.13 million deaths) per year $[9,42-45$, 47-50]. Autoimmune disease was associated with 10,000 deaths per year $(0.2 \%)[9,44]$.

Data from the GBD tool showed that the comparable disease burden was highest in oncology (38.4 million DALYs lost per year per population), largely driven by early mortality (YLL per year per population) (Fig. 1) [9]. The fewest DALYs were lost to autoimmune disease, primarily driven by morbidity. Within the three diseases, oncology contributed the greatest DALY burden ( $82 \%$ of DALYs lost) and the highest loss of life (93\% of YLL burden) (Table 1). A total of 5.5 million DALYs were lost per year to diabetes, driven by both early mortality and disability (YLD per year per population). Diabetes was associated with the highest
Table 1 Proportion of morbidity, mortality (DALYs, YLL and YLD) and disability weight in the three therapy areas $[9,51]$

\begin{tabular}{|c|c|c|c|c|}
\hline \multirow[t]{2}{*}{ Therapy area } & \multicolumn{3}{|c|}{$\begin{array}{l}\text { Proportion of morbidity and mortality with } \\
\text { each condition across the three therapy areas } \\
(\%)\end{array}$} & \multirow[t]{2}{*}{ Disability weights } \\
\hline & DALYs & YLL & YLD & \\
\hline Oncology & 82 & 93 & 24 & $\begin{array}{l}0.05-0.20 \text { (site-specific range) } \\
0.75 \text { (metastatic) } \\
0.81 \text { (terminal) }\end{array}$ \\
\hline Autoimmune disease & 6 & 1 & 30 & $\begin{array}{l}0.199 \text { (RA) } \\
0.056 \text { (skin diseases) }\end{array}$ \\
\hline Diabetes & 12 & 6 & 46 & $0.015^{\mathrm{a}}$ \\
\hline Total & 100 & 100 & 100 & \\
\hline
\end{tabular}

$D A L Y s$ disability-adjusted life-years, $R A$ rheumatoid arthritis, $Y L D$ years of life lost due to disability, $Y L L$ years of life lost

${ }^{\text {a }}$ Weights also available for some complications 


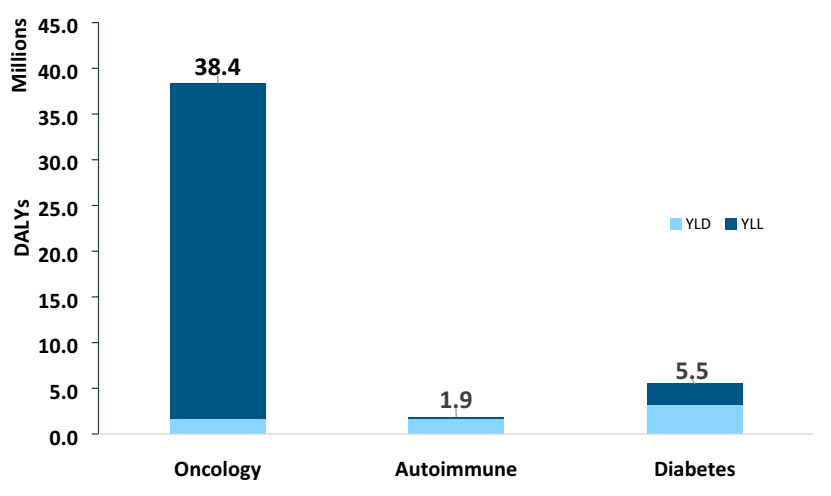

Fig. 1 Disability-adjusted life-years lost across the three therapy areas in the EU-28 [9]. EU-28 European Union-28, $Y L D$ years of life lost due to disability, YLL years of life lost

disability burden (46\% of YLD), almost double the burden associated with oncology (Table 1). Although the disability weights applied to oncology and autoimmune disease are higher than those applied to diabetes, the higher prevalence of diabetes drove higher DALYs compared with autoimmune disease (Table 1).

\subsubsection{Economic Burden Findings}

At the population level, diabetes was associated with the highest direct healthcare costs but the lowest drug spend, both in absolute terms and as a proportion of total costs (Fig. 2). Total direct costs in diabetes were $€ 93.0$ billion compared with $€ 70.0$ billion in oncology and $€ 57.2$ billion in autoimmune disease, whereas drug costs were $€ 6.4$ billion (7\% of total spend), $€ 26.3$ billion (38\%) and $€ 12.0$ billion (21\%), respectively [6, 42, 46, 52-69]. However, at the per-patient level, oncology was associated with the highest total costs (Fig. 2), with a mean annual drug spend of $€ 2789$ for oncology, €937 for autoimmune diseases and €247 for diabetes, highlighting the huge incremental costs associated with oncology medication [6, 42, 46, 52-69].

\subsection{Comparison of Changes in Drug Spend Versus Clinical Burden}

The incidence of oncology increased modestly over time, rising from 546 per 100,000 per year in 2012 to 574 per 100,000 per year in 2016 [9]. The incidence of autoimmune disease and diabetes varied slightly from 237 to 238 per 100,000 and from 253 to 249 per 100,000 between 2012 and 2016, respectively [9]. The prevalence of oncology rose only slightly over the same period, whereas the prevalence of autoimmune disease and diabetes marginally increased and decreased, respectively [9]. However, drug spend growth in oncology substantially outpaced the minor increase in prevalence (Fig. 3). Drug spend growth in autoimmune disease also surpassed the increase in prevalence. In contrast, drug spend growth in diabetes was more modest in relation to changes in prevalence (Fig. 3).

Mortality and morbidity in oncology changed marginally between 2012 and 2016, and substantial increases in drug spend were observed; drug spend CAGR was $10 \%$ compared

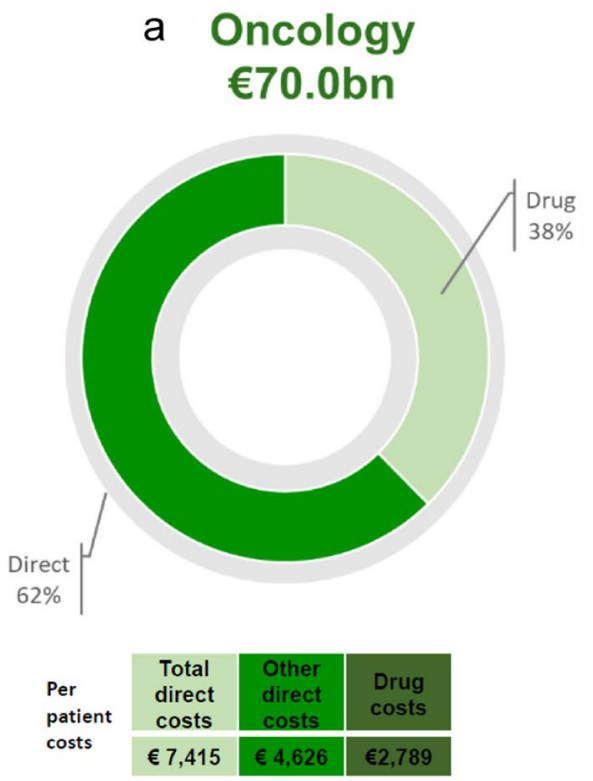

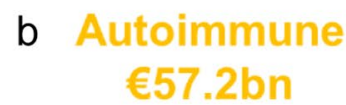

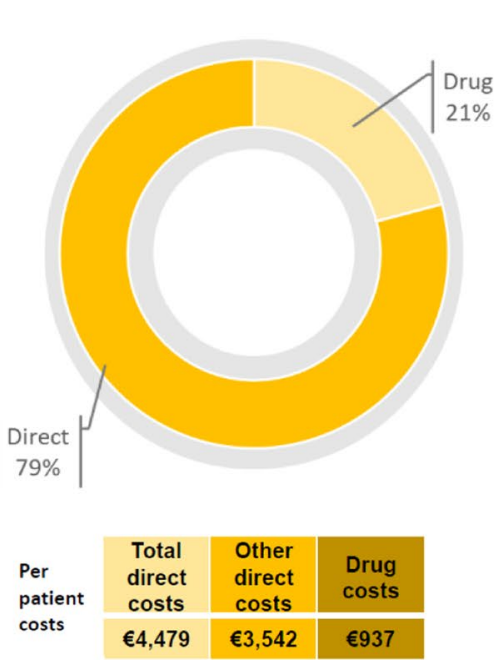

c Diabetes $€ 93.0 \mathrm{bn}$

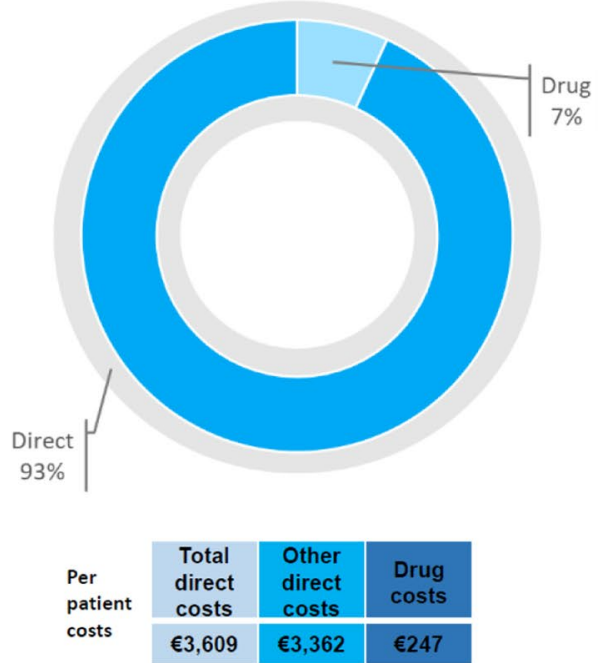

Fig. 2 a-c Total population and per patient direct healthcare costs across the three therapy areas in the EU-28 [6, 42, 46, 52-69]. EU-28 European Union-28 
a Oncology

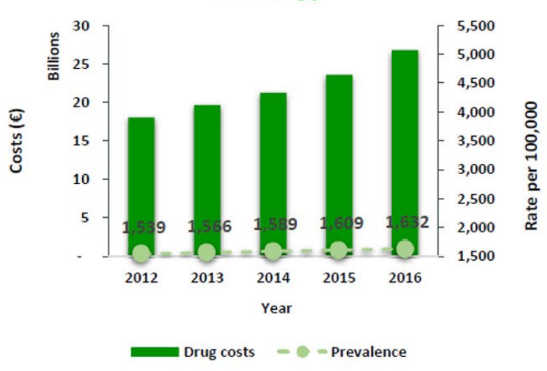

b Autoimmune

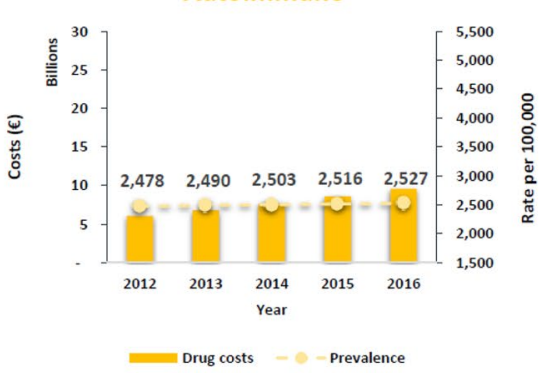

C Diabetes

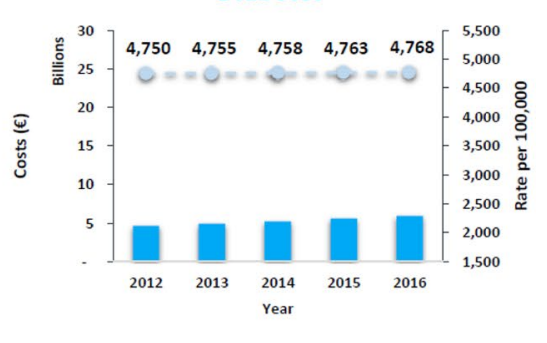

Fig. 3 Drug spend growth in relation to prevalence across the three therapy areas in the European Union-28 (EU-28) [6, 9]. EU-28 European Union-28
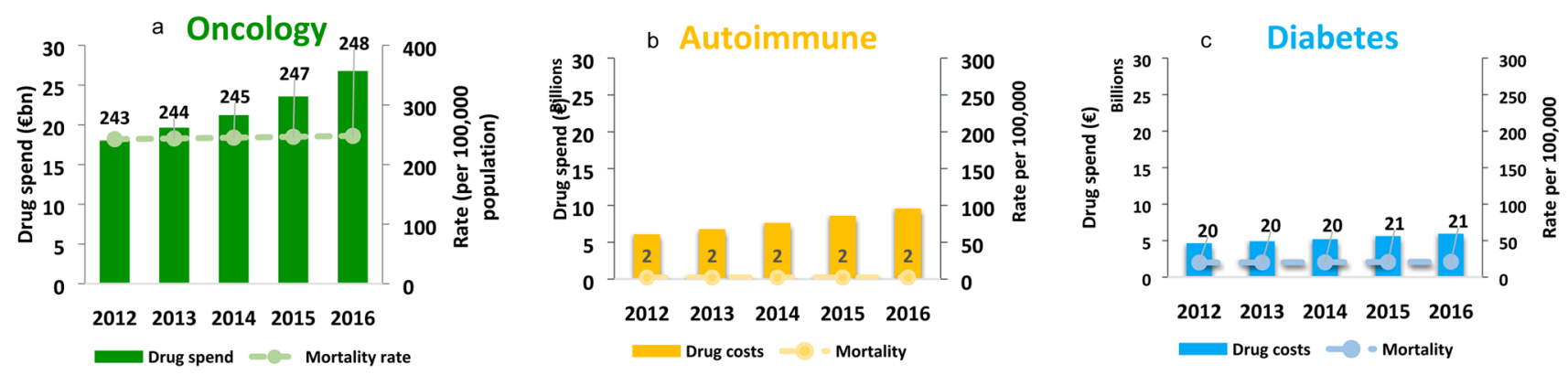

d
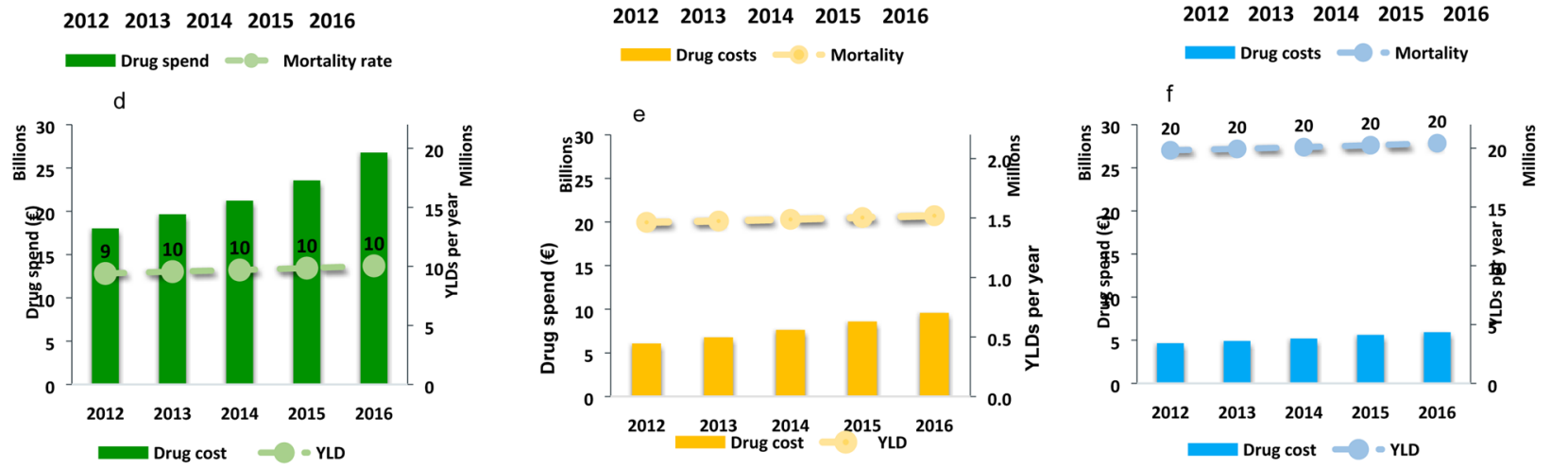

Fig. 4 a-f Drug spend growth in relation to mortality and morbidity across the three therapy areas in the EU-28 [6, 9]. EU-28 European Union28, YLDs Years lost due to disability

with a mortality rate CAGR of $0.56 \%$ (Fig. 4) [9]. In autoimmune disease, drug spend increases (CAGR 12\%) also outpaced the small increase in morbidity (CAGR 0.94\%), whereas, in diabetes, drug spend, morbidity and mortality remained stable (Fig. 4).

\subsection{Health Economic Value of Drug Spend in Each Therapy Area}

Analysis of the recent UK HTA submissions indicated that more QALYs were achieved per $€ 1000$ spent in diabetes compared with oncology or autoimmune disease (Fig. 5; Table 6 in the ESM). The average QALYs gained per $€ 1000$ spent was 0.023 in oncology, 0.213 in autoimmune disease and 0.639 in diabetes. The average ICER was $€ 47,552$ in oncology, $€ 31,917$ in autoimmune disease and $€ 12,522$ in diabetes (Fig. 5).

\section{Discussion}

Historical drug sales were substantially higher in oncology than in diabetes or autoimmune disease, with growth in oncology drug spend over the same period also surpassing that in diabetes and autoimmune disease. Forecast drug sales also indicated that the highest drug spend growth is expected in oncology, with double the growth versus diabetes. The targeted literature search indicated that diabetes has a higher prevalence than oncology or autoimmune disease in the EU-28, leading to the highest total healthcare costs but the lowest drug spend. 
Value of $€ 1,000$ spent

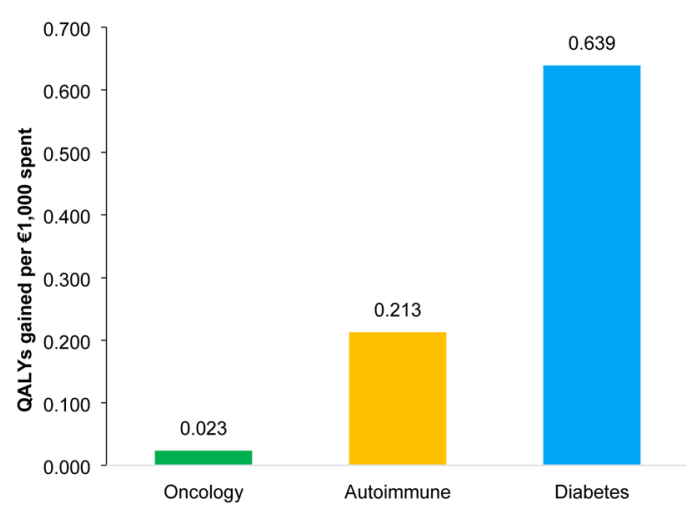

b Average ICER across each disease

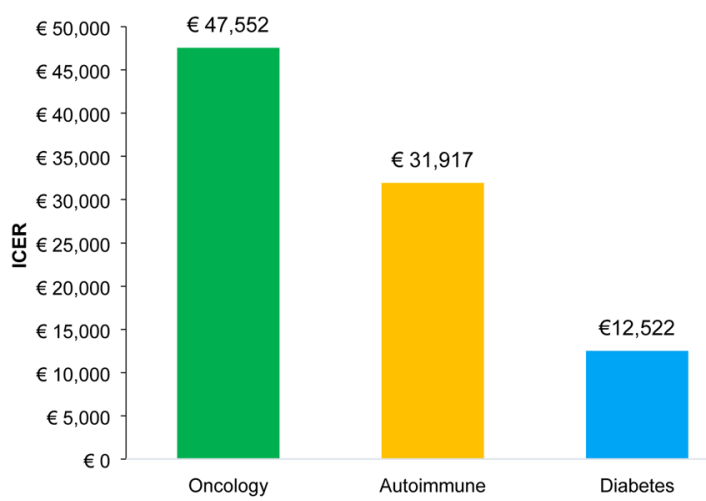

Fig. 5 a-b Average QALYs and ICERs in each therapy area from the analysis of UK HTA submissions [10-39]. HTA health technology assessment, ICER incremental cost effectiveness ratio, $Q A L Y$ quality adjusted life year

The European prevalence of diabetes is currently estimated at 29 million people. However, several studies suggested that the disease burden might be underestimated, and the WHO indicated that half of patients with diabetes might remain undiagnosed in Europe [70-72]. A hospital admission records study found that recording diabetes as a comorbidity was omitted in $41 \%$ of admissions [71]. Such omissions are likely to lead to underestimation of the number of diabetes-associated hospitalisations and deaths [71]. Indeed, a study in Germany estimated that $21 \%$ of all deaths in the country were attributable to diabetes, which is substantially higher than figures based on what death certificates would suggest [72].

The IDF projects a growth in diabetes prevalence of $15 \%$ by 2045 to 33 million; the OECD projects a higher growth of $23 \%$ by 2030 to 36 million [46]. These growth rates amount to 4-7 million additional individuals with diabetes in Europe. No credible EU-28 estimates of future oncology and autoimmune disease prevalence were found. The absolute global economic burden of diabetes was projected to increase from \$US1.3 trillion in 2015 to \$US2.1-2.5 trillion by 2030 [73]. Sub-optimal control of modifiable risk factors such as diet, exercise, overweight and obesity account for approximately $80 \%$ of the increase in diabetes prevalence [70]. Diabetes prevalence is higher in socioeconomically disadvantaged groups, likely as a result of poorer access to high-quality healthcare as well as environmental factors that predispose towards less healthy lifestyles [70].

Many of the modifiable risk factors for diabetes also contribute to the development of cancer. Furthermore, approximately $2 \%$ of cancers are linked to underlying diabetes, rising to $5.5 \%$ when high body mass index (BMI) is included [74]. Applying this to the EU-28 suggests that diabetes could lead to 190,000 cancer cases per year, rising to over 500,000 when excess BMI is included. These cases may potentially be avoided through better management of diabetes and focused attention on lifestyle changes.

Not only are risk factors for the development of diabetes rising in prevalence but also diabetes control among the EU-28 nations varies substantially. A high proportion of countries have less than half of patients meeting the glycated haemoglobin (HbA1c) target of 7\% [75]. Given the projected rise in diabetes prevalence, current poor management and its potential role in the development of cancer, there may be value in improving care in diabetes and controlling BMI because of the likely impact in reducing the clinical and economic burden both of diabetes itself and of cancer.

Surrogate endpoints such as HbAlc are necessary endpoints in chronic diseases since life-long trials are not feasible and patients are being treated to avoid long-term complications. However, for example, under the German AMNOG system, lowering of blood glucose level in type 2 diabetes mellitus (T2DM) is not recognised as an 'endpoint' that is relevant for patients. This is despite the fact that, for a patients with diabetes, blood glucose level is the primary way to measure treatment benefit [76] and changes in $\mathrm{HbA} 1 \mathrm{c}$ levels have been proven to have long-term effects on the risk of microvascular complications and some macrovascular complications [77, 78]. Similarly, weight loss is not recognised as a patient-relevant endpoint even though obesity is known to be the main risk factor for a number of non-communicable diseases such as cardiovascular disease, T2DM, hypertension, coronary heart disease, and certain cancers [79]. Therefore, the link between these surrogate endpoints and patient outcomes should be continually evaluated and recognised.

This study also demonstrated that substantial increases in oncology drug spend did not correspond to short-term reductions in mortality or morbidity. Likewise, drug spend 
increases in autoimmune disease have not coincided with reductions in morbidity, whereas drug spend changes in diabetes have more closely matched changes in morbidity and mortality. Given the drug spend changes in diabetes, it is important to note that T2DM often has significantly greater drug costs associated with the disease than type 1 diabetes mellitus. It is known that concentrating more funds on the prevention and treatment of diabetes will lead to reductions in complications and treatment, which can possibly reverse disease $[80,81]$.

Moreover, UK HTA submissions indicate that greater health economic value is obtained through spending in diabetes compared with oncology or autoimmune disease. The QALY benefit per $€$ was 27 times higher in diabetes than in oncology and three times higher in diabetes than in autoimmune diseases. However, drug spend may not always be proportional to disease burden, for example, at times of rapid innovations in drug discovery. There may also be a lag time between increases in drug spend and tangible changes in key outcomes such as mortality. In addition, the decision to fund individual drugs is influenced by a range of factors [82]. Decision makers and society often rank mortality as more important than morbidity, leading to prioritisation of oncology over other diseases because of societal preferences [82]. Likewise, because orphan diseases tend to have a particularly high burden to individuals (albeit a relatively low burden to society), funding for these conditions is also often prioritised [83]. These considerations must be considered when judging the value of money spent. The present study provides insights that should stimulate debate and lead to further investigation. Indeed, some countries have specific funding arrangements for oncology drugs (e.g. the UK Cancer Drugs Fund) [82], and many countries have special procedures in place for licensing of orphan drugs $[84,85]$. European countries are currently adopting several new approaches to balance the use of new medicines against rising costs, including the use of multiple criteria decision analysis tools, particularly in oncology and orphan diseases $[1,86]$.

We adopted a robust methodology to find each metric of interest, but the evidence available on target parameters at the EU-28 level was more limited than at the individual country level. Where EU-28 level data were unavailable, regional or country level data were not extrapolated as this may not have been representative across the region. This approach limited the total number of studies available. A further limitation was that clinical and economic outputs were informed by research from a number of independent studies, which in some cases adopted different methodological approaches to generate parameter estimates. As such, results across indications might not be perfectly comparable in all cases as the parameter estimates were not adjusted to account for variations between studies or diseases such as different cancer types. Drug forecast data over 5 years are speculative, so inferences from this analysis must be limited. Drug cost data also do not consider discounts as the magnitude of discounts are unknown. Therefore, the drug cost data do not represent true drug spend.

Another important limitation was that precise estimates of indirect costs were not available for all diseases at the European level; as such, the full economic burden is likely to be underestimated. Furthermore, the oncology and diabetes mortality rates over time are driven by epidemiological and environment factors, not just drug spend, and there is likely to be a delay between oncology drug spending and observed mortality outcomes, further limiting inferences that can be made from the oncology trend analysis. Finally, autoimmune disease within this study included only rheumatoid arthritis, psoriasis, Crohn's disease and ulcerative colitis, which do not represent all autoimmune conditions.

The value of a $€$ spent was an exploratory analysis based on ten HTA submissions in each indication within the UK. This may limit generalisability to the EU-28 since the analysis is based on the UK preference of willingness to pay (WTP) for a QALY in each disease area where WTP thresholds vary between $£ 20,000$ and $£ 50,000$ depending on therapies classified for standard, end of life or very rare diseases [87]. While the UK attaches additional value to treatments that meet this end-of-life criteria, for example, extension of life in diseases with limited survival prognosis, this may be different in other countries across the EU-28. Furthermore, the QALY comparison is biased to the UK HTA process, which aims to provide a comparable metric across diseases as, for example, oncology has primary endpoints related to survival, whereas rheumatoid arthritis is not a disease mostly associated with mortality. While previous discussions have highlighted limitations associated with the QALY to compare value across diseases, including ethical, methodological and contextual shortfalls, it remains a suitable metric for evaluating health economic value because it is still considered the most rigorous methodological tool available and provides a robust framework [41]. The QALY is a metric that allows comparison of value across diseases, although many other European countries do not adopt it within the context of a cost-utility analysis as part of the HTA process. This is because assessments in Europe most often focus on clinical benefit and price separately. For example, in Germany, there is no competition for funds based on the QALY comparison as health economic benefit is not evaluated and hard endpoints are deemed more important to assess value.

The value-of-spend analysis was based on the calculation of unadjusted ICERs for each indication. Although value may be had in weighting ICERs according to their proportional use, there is difficulty in reflecting molecule weighting per indication accurately because many of the included drugs are used across indications and a limited 
number of HTA submissions were reviewed. For example, biosimilar drugs are used in RA, Crohn's disease and many other conditions. This level of granularity within each subindication was not available. Finally, HTA submissions with negative recommendations were included in this analysis for the oncology indication, but this is not expected to provide overly impactful interpretations since ICERs for these submissions were within the mid-range of all identified oncology ICERs.

\section{Conclusion}

This study indicates that, among the three therapy areas discussed, drug spend may not correlate to the clinical burden over a shorter time horizon. Further research into whether this observation continues over the longer term, and whether it is appropriate to link resource allocation to clinical burden, may reveal findings warranting further discussion. This could stimulate discussions about the availability of innovative products, resource prioritisation and whether the resource investment allocation weighting should be higher towards disease management, which could help to reduce costly complication expenditure. It is important to note that there may also be circumstances under which drug spend would not be expected to associate strongly with disease burden. For example, it may be appropriate to allocate additional spend to diseases with high unmet need or limited treatment options; however, it may not be optimal to allocate further resources to such diseases if no treatments are available or the potential to elicit value is limited. This analysis promotes consideration of a thorough debate of how drug expenditure is deployed and the criteria employed in healthcare resource allocation and prioritisation. Projections of future burden across all diseases would help inform appropriate resource allocation. Undertaking country-level assessments is likely to permit more precise characterisation of clinical and economic burden, hence individual country analyses may strengthen research findings. Finally, an appraisal of HTA submissions encompassing a greater volume of assessments would strengthen the robustness of the value-of-spend analysis, which is vital to articulate to healthcare payers.

Acknowledgements The authors thank Mary Greenacre for providing medical writing support.

\section{Declaration}

Funding This study was funded by Novo Nordisk.

Conflicts of interest KP and CJCB are employees of IQVIA Ltd and received funding from Novo Nordisk for the writing of this manuscript.
CH, TVRA and TV are employees of Novo Nordisk. WG has no conflicts of interest that are directly relevant to the content of this article.

Availability of data and material The MIDAS drug sales database is not publicly available as it is copyrighted by IQVIA Ltd. Companies can request the database for a fee.

Author's contributions All authors contributed to the study conception and design of the manuscript. KP and CJCB were involved in the analysis and manuscript drafts, and all authors commented on previous versions of the manuscript. All authors read and approved the final manuscript.

Open Access This article is licensed under a Creative Commons Attribution-NonCommercial 4.0 International License, which permits any non-commercial use, sharing, adaptation, distribution and reproduction in any medium or format, as long as you give appropriate credit to the original author(s) and the source, provide a link to the Creative Commons licence, and indicate if changes were made. The images or other third party material in this article are included in the article's Creative Commons licence, unless indicated otherwise in a credit line to the material. If material is not included in the article's Creative Commons licence and your intended use is not permitted by statutory regulation or exceeds the permitted use, you will need to obtain permission directly from the copyright holder. To view a copy of this licence, visit http://creativecommons.org/licenses/by-nc/4.0/.

\section{References}

1. Godman B, Bucsics A, Vella Bonanno P, Oortwijn W, Rothe CC, Ferrario A, et al. Barriers for access to new medicines: searching for the balance between rising costs and limited budgets. Front Public Health. 2018;6:328. https://doi.org/10.3389/fpubh .2018.00328.

2. Organisation for Economic Co-operation and Development. Pharmaceutical spending. 2018. https://www.oecd-ilibrary.org/socia 1-issues-migration-health/pharmaceutical-spending/indicator/engli sh_998febf6-en. Accessed September 2019.

3. Prasad V, Wang R, Afifi SH, Mailankody S. The rising price of cancer drugs-a new old problem? JAMA Oncol. 2017;3(2):277-8. https://doi.org/10.1001/jamaoncol.2016.4275.

4. Kelly RJ, Smith TJ. Delivering maximum clinical benefit at an affordable price: engaging stakeholders in cancer care. Lancet Oncol. 2014;15(3):e112-8. https://doi.org/10.1016/s1470 -2045(13)70578-3.

5. Espin J, Schlander M, Godman B, Anderson P, Mestre-Ferrandiz $\mathrm{J}$, Borget I, et al. Projecting pharmaceutical expenditure in EU5 to 2021: adjusting for the impact of discounts and rebates. Appl Health Econ Health Policy. 2018;16(6):803-17. https://doi. org/10.1007/s40258-018-0419-1.

6. IQVIA. MIDAS sales data. [Data on file]. 2018.

7. Organisation for economic co-operation and development. Consumer price indices (CPIs). 2018. https://stats.oecd.org/Index .aspx?QueryId=82183. Accessed February 2018.

8. Organisation for economic co-operation and development. Purchasing Power Parities for GDP and related indicators. 2018. https ://stats.oecd.org/Index.aspx?QueryId=25900. Accessed February 2018.

9. Global Health Data Exchange. Global Burden of Disease results tool. http://ghdx.healthdata.org/gbd-results-tool. Accessed September 2019. 
10. National Institute of Health and Care Excellence. Pembrolizumab for treating locally advanced or metastatic urothelial carcinoma after platinum-containing chemotherapy. Technology appraisal guidance [TA519]. 2018. https://www.nice.org.uk/guidance/ta519 . Accessed May 2018.

11. National Institute of Health and Care Excellence. Avelumab for treating metastatic Merkel cell carcinoma. Technology appraisal guidance [TA517]. 2018. https://www.nice.org.uk/guidance/ta517 . Accessed May 2018.

12. National Institute of Health and Care Excellence. Eribulin for treating locally advanced or metastatic breast cancer after 1 chemotherapy regimen. Technology appraisal guidance [TA515]. 2018. https://www.nice.org.uk/guidance/ta515. Accessed May 2018.

13. National Institute of Health and Care Excellence (NICE). Cabozantinib for treating medullary thyroid cancer: Technology appraisal guidance [TA516]. 2018. https://www.nice.org.uk/guida nce/ta516 Accessed September 2018.

14. National Institute of Health and Care Excellence (NICE). Tivozanib for treating advanced renal cell carcinoma: Technology appraisal guidance [TA512]. 2018. https://www.nice.org.uk/guida nce/ta512. Accessed May 2018.

15. National Institute of Health and Care Excellence (NICE). Regorafenib for previously treated advanced hepatocellular carcinoma: Technology appraisal guidance [TA514]. 2018. https:// www.nice.org.uk/guidance/ta514 Accessed May 2018.

16. National Institute of Health and Care Excellence (NICE). Daratumumab monotherapy for treating relapsed and refractory multiple myeloma: Technology appraisal guidance [TA510]. 2018. https:// www.nice.org.uk/guidance/ta510. Accessed May 2018.

17. National Institute of Health and Care Excellence (NICE). Ixazomib with lenalidomide and dexamethasone for treating relapsed or refractory multiple myeloma: Technology appraisal guidance [TA505]. 2018. https://www.nice.org.uk/guidance/ta516. Accessed May 2018.

18. National Institute of Health and Care Excellence (NICE). Fulvestrant for untreated locally advanced or metastatic oestrogenreceptor positive breast cancer: Technology appraisal guidance [TA503]. 2018. https://www.nice.org.uk/guidance/ta505. Accessed May 2018.

19. National Institute of Health and Care Excellence (NICE). Sarilumab for moderate to severe rheumatoid arthritis: Technology appraisal guidance [TA485]. 2017. https://www.nice.org.uk/guida nce/ta503 Accessed May 2018.

20. National Institute of Health and Care Excellence (NICE). Tofacitinib for moderate to severe rheumatoid arthritis: Technology appraisal guidance [TA480]. 2017. https://www.nice.org.uk/guida nce/ta503 Accessed May 2018.

21. National Institute of Health and Care Excellence (NICE). Eluxadoline for treating irritable bowel syndrome with diarrhoea: Technology appraisal guidance [TA471]. 2017. https://www.nice.org. uk/guidance/ta503 Accessed May 2018.

22. National Institute of Health and Care Excellence (NICE). Ustekinumab for moderately to severely active Crohn's disease after previous treatment: Technology appraisal guidance [TA456]. 2017. https://www.nice.org.uk/guidance/ta503. Accessed May 2018.

23. National Institute of Health and Care Excellence (NICE). Brodalumab for treating moderate to severe plaque psoriasis: Technology appraisal guidance [TA511]. 2018. https://www.nice.org.uk/guida nce/ta503. Accessed May 2018.

24. National Institute of Health and Care Excellence (NICE). Dimethyl fumarate for treating moderate to severe plaque psoriasis. 2017. https://www.nice.org.uk/guidance/TA475. Accessed January 2020.

25. National Institute of Health and Care Excellence (NICE). Baricitinib for moderate to severe rheumatoid arthritis: Technology appraisal guidance [TA466]. 2017. https://www.nice.org.uk/guida nce/ta503 Accessed May 2018.

26. National Institute of Health and Care Excellence (NICE). Vedolizumab for treating moderately to severely active Crohn's disease after prior therapy: Technology appraisal guidance [TA352]. 2015. https://www.nice.org.uk/guidance/ta503. Accessed May 2018.

27. National Institute of Health and Care Excellence (NICE). Ixekizumab for treating moderate to severe plaque psoriasis: Technology appraisal guidance [TA442]. . 2017. https://www.nice.org.uk/ guidance/ta503. Accessed May 2018.

28. National Institute of Health and Care Excellence (NICE). Ustekinumab for the treatment of adults with moderate to severe psoriasis: Technology appraisal guidance [TA180]. 2017. https://www. nice.org.uk/guidance/ta503. Accessed May 2018.

29. National Institute of Health and Care Excellence (NICE). Dapagliflozin in triple therapy for treating type 2 diabetes: Technology appraisal guidance [TA418]. 2016. https://www.nice.org. uk/guidance/ta503. Accessed May 2018.

30. National Institute of Health and Care Excellence (NICE). Canagliflozin, dapagliflozin and empagliflozin as monotherapies for treating type 2 diabetes: Technology appraisal guidance [TA390]. 2016. https://www.nice.org.uk/guidance/ta503 . Accessed May 2018.

31. National Institute of Health and Care Excellence (NICE). Empagliflozin in combination therapy for treating type 2 diabetes: Technology appraisal guidance [TA336]. 2015. https://www. nice.org.uk/guidance/ta503. Accessed May 2018.

32. National Institute of Health and Care Excellence (NICE). Continuous subcutaneous insulin infusion for the treatment of diabetes mellitus: Technology appraisal guidance [TA151]. 2008. https://www.nice.org.uk/guidance/ta503. Accessed May 2018.

33. Scottish Medicines Consortium (SMC). Liraglutide $6 \mathrm{mg} / \mathrm{mL}$ prefilled pen for injection ( $3 \mathrm{~mL}$ ) (Victoza) Scottish Medicines Consortium guidance [SMC ID 585/09]. 2009.

34. Scottish Medicines Consortium (SMC). Exenatide, 5 or 10 micrograms, solution for injection, prefilled pen (Byetta $\left.{ }^{\circledR}\right)$ Scottish Medicines Consortium guidance [SMC ID 376/07]. 2007. https://www.scottishmedicines.org.uk/medicines-advice/exena tide-5-or-10-micrograms-solution-for-injection-prefilled-penbyetta-fullsubmission-37607/. Accessed May 2018.

35. Scottish Medicines Consortium (SMC). Saxagliptin, $5 \mathrm{mg}$ filmcoated tablet (Onglyza ) Scottish Medicines Consortium guidance [SMC ID 603/10]. 2010. https://www.scottishmedicin es.org.uk/medicinesadvice/saxagliptin-onglyza-fullsubmis sion-60310/. Accessed May 2018.

36. Scottish Medicines Consortium (SMC). Liraglutide $6 \mathrm{mg} / \mathrm{mL}$ prefilled pen for injection $(3 \mathrm{~mL})$ (Victoza $\left.{ }^{\circledR}\right)$ Scottish Medicines Consortium guidance [SMC ID 1044/15]. 2015. https://www. scottishmedicines.org.uk/medicines-advice/liraglutide-victozafullsubmission-104415/. Accessed May 2018.

37. Scottish Medicines Consortium (SMC). Sitagliptin 100mg tablets (Januvia $\left.{ }^{\circledR}\right)$ Scottish Medicines Consortium guidance [SMC ID 408/07]. 2007. https://www.scottishmedicines.org.uk/medic inesadvice/sitagliptin-januvia-fullsubmission-40807/. Accessed May 2018.

38. Scottish Medicines Consortium (SMC). Exenatide $2 \mathrm{mg}$ powder and solvent for prolonged-release suspension forinjection (Bydureon $\left.{ }^{\circledR}\right)$ Scottish Medicines Consortium guidance [SMC ID 748/11]. 2011.

39. Tappenden P, Carroll C, Hamilton J, Kaltenthaler E, Wong R, Wadsley $\mathrm{J}$ et al. Cabozantinib and vandetanib for treating unresectabe locally advanced or metastatic medullary thyroid cancer. Technology assessment report: final report to the National Institute for Health and Care Excellence. 2017. 
40. Whitehead SJ, Ali S. Health outcomes in economic evaluation: the QALY and utilities. Br Med Bull. 2010;96(1):5-21. https:// doi.org/10.1093/bmb/ldq033.

41. Pettitt DA, Raza S, Naughton B, Roscoe A, Ramakrishnan A, Ali A, et al. The limitations of QALY: a literature review. J Stem Cell Res Ther. 2016. https://doi.org/10.4172/2157-7633.1000334.

42. European Society for Medical Oncology. The burden and cost of cancer. Annals of Oncology. 2007;18(3): 8-22.

43. Ferlay J, Steliarova-Foucher E, Lortet-Tieulent J, Rosso S, Coebergh JW, Comber H, et al. Cancer incidence and mortality patterns in Europe: estimates for 40 countries in 2012. Eur J Cancer. 2013;49(6):1374-403. https://doi.org/10.1016/j.ejca.2012.12.027.

44. World Health Organization. WHO Europe Data and Statistics.

45. World Health Organization. All Cancers (excluding non-melanoma skin cancer) Estimated Incidence, Mortality and Prevalence Worldwide in 2012.2018.

46. International Diabetes Federation. IDF Diabetes Atlas, 8th edition. 2017. www.diabetesatlas.org. Accessed September 2019.

47. Malvezzi M, Bertuccio P, Rosso T, Rota M, Levi F, La Vecchia C, et al. European cancer mortality predictions for the year 2015: does lung cancer have the highest death rate in EU women? Ann Oncol. 2015;26(4):779-86. https://doi.org/10.1093/annonc/mdv00 1.

48. Malvezzi M, Carioli G, Bertuccio P, Boffetta P, Levi F, La Vecchia C, et al. European cancer mortality predictions for the year 2017, with focus on lung cancer. Ann Oncol. 2017;28(5):1117-23. https ://doi.org/10.1093/annonc/mdx033.

49. Polić-Vižintin M, Štimac D, Badanjak A, Duvnjak LS. Diabetes mellitus as public health priority in Zagreb, Croatia (2001-2009). Epidemiol Genet. 2012;26:59.

50. International Diabetes Federation. IDF Diabetes Atlas. 2018.

51. World Health Organization. Global burden of disease 2004 update: disability weights for diseases and conditions. https://www.who. int/healthinfo/global_burden_disease/GBD2004_DisabilityWeigh ts.pdf. Accessed January 2020.

52. Luengo-Fernandez R, Leal J, Gray A, Sullivan R. Economic burden of cancer across the European Union: a population-based cost analysis. Lancet Oncol. 2013;14(12):1165-74. https://doi. org/10.1016/S1470-2045(13)70442-X.

53. European parliament research service. European Union action on cancer. 2018. http://www.europarl.europa.eu/RegData/etude s/ATAG/2017/599246/EPRS_ATA\%282017\%29599246_EN.pdf Accessed April 2018.

54. Hanly P, Soerjomataram I, Sharp L. Measuring the societal burden of cancer: The cost of lost productivity due to premature cancerrelated mortality in Europe. Int J Cancer. 2015;136(4):E136-45. https://doi.org/10.1002/ijc.29105.

55. Office of Health Economics, The Swedish Institute for Health Economics. Improving efficiency and resource allocation in future cancer care 2016.

56. Wilking NE, Hofmarcher T, Lindgren P, Jonsson B. The burden and direct cost of cancer in Europe (EU-28). J Clin Oncol. 2016;34(15):6618.

57. Jonsson B, Hofmarcher T, Lindgren P, Wilking N. The cost and burden of cancer in the European Union 1995-2014. Eur J Cancer. 2016;66:162-70. https://doi.org/10.1016/j.ejca.2016.06.022.

58. Philipson T, Eber M, Lakdawalla DN, Corral M, Conti R, Goldman DP. An analysis of whether higher health care spending in the United States versus Europe is "worth it" in the case of cancer. Health Aff (Millwood). 2012;31(4):667-75. https://doi. org/10.1377/hlthaff.2011.1298.

59. Burisch J, Kaimakliotis J, Duricova D, Kievit L, Dahlerup JF, Salupere R et al., editors. Unchanged surgery and hospitalization rates in an East-West European inception cohort despite differences in use of biologicals-3-year follow-up of the ECCO-EpiCom Cohort2015.
60. P. L. The economic aspects of IBD. Hépato-Gastro \& Oncologie Digestive. 2015;22(2).

61. O'Hara J, Rose A, Jacob I, Burke T, S. W. The Burden of Rheumatoid Arthritis across Europe: a Socioeconomic Survey (BRASS): National Rheumatoid Arthritis Society.

62. Gulacsi L, Brodszky V, Baji P, Kim H, Kim SY, Cho YY, et al. Biosimilars for the management of rheumatoid arthritis: economic considerations. Expert Rev Clin Immunol. 2015;11(Suppl 1):S4352. https://doi.org/10.1586/1744666X.2015.1090313.

63. Lundkvist J, Kastang F, Kobelt G. The burden of rheumatoid arthritis and access to treatment: health burden and costs. Eur J Health Econ. 2008;8(Suppl 2):S49-60. https://doi.org/10.1007/ s10198-007-0088-8.

64. Obradors M, Figueras M, Paz S, Comellas M, Lizan L. Costs of psoriasis in Europe. A systematic review of the literature. Value Health. 2014;17(7):A606. https://doi.org/10.1016/j. jval.2014.08.2112.

65. Zhang P, Zhang X, Brown J, Vistisen D, Sicree R, Shaw J, et al. Global healthcare expenditure on diabetes for 2010 and 2030. Diabetes Res Clin Pract. 2010;87(3):293-301. https://doi. org/10.1016/j.diabres.2010.01.026.

66. European Diabetes Leadership Forum. The diabetes epidemic and its impact on Europe2018.

67. The Diabetes Council. Cost of Diabetes vs Other Diseases - In the US and Globally. 2016. https://www.thediabetescouncil.com/ cost-diabetes-vs-diseases-us-globally. Accessed April 2018).

68. Health and Environment Alliance (HEAL). Health Costs in the European Union. How much is related to EDCS.2014.

69. World Health Organization. Diabetes epidemic in Europe. 2011.

70. World Health Organization. Diabetes. Data and statistics. 2018. http://www.euro.who.int/en/health-topics/noncommunicable -diseases/diabetes/data-and-statistics. Accessed November 2019.

71. Anwar H, Fischbacher CM, Leese GP, Lindsay RS, McKnight JA, Wild SH. Assessment of the under-reporting of diabetes in hospital admission data: a study from the Scottish Diabetes Research Network Epidemiology Group. Diabet Med. 2011;28(12):1514-9. https://doi.org/10.1111/j.1464-5491.2011.03432.x.

72. Jacobs E, Hoyer A, Brinks R, Kuss O, Rathmann W. Burden of mortality attributable to diagnosed diabetes: a nationwide analysis based on claims data from 65 million people in Germany. Diabetes Care. 2017;40(12):1703-9. https://doi.org/10.2337/dc17-0954.

73. Bommer C, Sagalova V, Heesemann E, Manne-Goehler J, Atun $\mathrm{R}$, Barnighausen T, et al. Global economic burden of diabetes in adults: projections from 2015 to 2030. Diabetes Care. 2018;41(5):963-70. https://doi.org/10.2337/dc17-1962.

74. Pearson-Stuttard J, Zhou B, Kontis V, Bentham J, Gunter MJ, Ezzati M. Worldwide burden of cancer attributable to diabetes and high body-mass index: a comparative risk assessment. Lancet Diabetes Endocrinol. 2018;6(6):e6-15. https://doi.org/10.1016/ s2213-8587(18)30150-5.

75. Euro Health Consumer Index. Health Consumer Powerhouse. 2017. https://healthpowerhouse.com/media/EHCI-2017/EHCI2017-report.pdf. Accessed June 2018).

76. Staab T, Isbary G, Amelung VE, Ruof J. Inconsistent approaches of the G-BA regarding acceptance of primary study endpoints as being relevant to patients-an analysis of three disease areas: oncological, metabolic, and infectious diseases. BMC Health Serv Res. 2016;16(1):651. https://doi.org/10.1186/s12913-016-1902-8.

77. Intensive blood-glucose control with sulphonylureas or insulin compared with conventional treatment and risk of complications in patients with type 2 diabetes (UKPDS 33). UK Prospective Diabetes Study (UKPDS) Group. Lancet. 1998;352(9131):837-53.

78. Holman RR, Paul SK, Bethel MA, Matthews DR, Neil HA. 10-year follow-up of intensive glucose control in type 2 diabetes. N Engl J Med. 2008;359(15):1577-89. https://doi.org/10.1056/ NEJMoa0806470. 
79. Leitner DR, Fruhbeck G, Yumuk V, Schindler K, Micic D, Woodward E, et al. Obesity and type 2 diabetes: two diseases with a need for combined treatment strategies-EASO can lead the way. Obes Facts. 2017;10(5):483-92. https://doi.org/10.1159/00048 0525 .

80. Hallberg SJ, Gershuni VM, Hazbun TL, Athinarayanan SJ. Reversing type 2 diabetes: a narrative review of the evidence. Nutrients. 2019. https://doi.org/10.3390/nu11040766.

81. Zhuo X, Zhang P, Barker L, Albright A, Thompson TJ, Gregg E. The lifetime cost of diabetes and its implications for diabetes prevention. Diabetes Care. 2014;37(9):2557-64. https://doi. org/10.2337/dc13-2484.

82. Haycox A. Why cancer? PharmacoEconomics. 2016;34(7):625-7. https://doi.org/10.1007/s40273-016-0413-0.

83. Simoens S, Picavet E, Dooms M, Cassiman D, Morel T. Costeffectiveness assessment of orphan drugs: a scientific and political conundrum. Appl Health Econ Health Policy. 2013;11(1):1-3. https://doi.org/10.1007/s40258-012-0004-y.
84. Gammie T, Lu CY, Babar ZU. Access to orphan drugs: a comprehensive review of legislations, regulations and policies in 35 countries. PLoS ONE. 2015;10(10):e0140002. https://doi.org/10.1371/ journal.pone.0140002.

85. Stawowczyk E, Malinowski KP, Kawalec P, Bobinski R, Siwiec J, Panteli D, et al. Reimbursement status and recommendations related to orphan drugs in European countries. Front Pharmacol. 2019;10:1279. https://doi.org/10.3389/fphar.2019.01279.

86. Godman B, Malmstrom RE, Diogene E, Gray A, Jayathissa S, Timoney A, et al. Are new models needed to optimize the utilization of new medicines to sustain healthcare systems? Expert Rev Clin Pharmacol. 2015;8(1):77-94. https://doi.org/10.1586/17512 433.2015.990380.

87. Paulden M. Recent amendments to NICE's value-based assessment of health technologies: implicitly inequitable? Expert Rev Pharmacoecon Outcomes Res. 2017;17(3):239-42. https://doi. org/10.1080/14737167.2017.1330152. 